\section{Batch study, equilibrium and kinetics of adsorption of naphthalene using waste tyre rubber granules} Felix A. Aisien, Andrew N. Amenaghawon,
Albert I. Adinkwuye

Department of Chemical Engineering, University of Benin, Nigeria

\section{Abstract}

The potential use of waste tyre rubber granules (WTRG) for the batch adsorption of naphthalene from aqueous solutions was investigated. The effect of various operational variables such as contact time, initial naphthalene concentration, adsorbent dose, size of adsorbent particles, and temperature of solution on the adsorption capacity of WTRG was evaluated. The adsorption of naphthalene by WTRG was a fast kinetic process with an equilibrium contact time of $60 \mathrm{~min}$. A low temperature $\left(5^{\circ} \mathrm{C}\right)$, small adsorbent particle size $(0.212 \mathrm{~mm})$ and higher adsorbent dosage favored the adsorption process. Results of isotherm studies revealed that adsorption of naphthalene was best described by the Langmuir isotherm equation $\left(R^{2}=0.997\right)$ while the kinetics of the process was best described by the Lagergren pseudofirst order kinetic equation $\left(\mathrm{R}^{2}=0.998\right)$. This study has demonstrated the suitability of WTRG for the removal of naphthalene from aqueous solution.

\section{Introduction}

Serious water pollution problems are still commonplace even in the face of the many existing environmental protection regulations. Naphthalene belongs to the family of hydrocarbons referred to as polycyclic aromatic hydrocarbons (PAHs). These compounds enter the environment through two major avenues which are natural and anthropogenic. Natural sources of PAHs include volcanic eruptions and forest fires. They also enter the environment through a host of anthropogenic activities mainly incomplete combustion of fossil fuels for power generation. ${ }^{1-3}$ Naphthalene contaminated wastewater results from industrial and domestic effluents, leaks of PAHs containing materials such as petroleum fractions, creosote and pharmaceutical waste. ${ }^{4}$ The United States Environmental Protection Agency (USEPA) has classified naphthalene as a priority pollutant as a result of its carcinogenic and mutagenic effects on humans. ${ }^{5}$
Various methods for removing naphthalene from aqueous solutions including photocatalytic oxidation, biodegradation using surfactants, electron beam irradiation, ozonation and adsorption using zeolites and activated carbon have been reported. ${ }^{6-11}$ Adsorption remains the best option for the removal of naphthalene from solution as it can generally remove the compound in a simple and easy operation. However, the high cost associated with the use of activated carbon and other special adsorbents limits their applicability in treating large volumes of contaminated effluents.

An estimated 10 billion waste tyres are discarded annually worldwide. ${ }^{12}$ In Nigeria alone, the current estimate stands at about 21 million waste tyres which are discarded every year. ${ }^{13}$ These waste tyres represent a major environmental problem as only a small fraction of it is recycled to value added product such as floor mats, tyre derived fuels, liquid waste treatment, incorporation into asphalt for road pavement etc while the majority of it is often discarded inappropriately as it is done in developing countries. ${ }^{14,15}$ Alternative use instead of disposal appears to be a potentially sustainable solution to the environmental problem posed by the waste tyres. ${ }^{16}$

A lot of interest has been shown in the use of waste tyre rubber in the removal of organics from polluted wastewater. ${ }^{12,13,15-17}$ In comparison with conventional adsorbent, waste tyre rubber granules offers the advantage of being readily available and low cost. They have been applied to the treatment of contaminated effluents in different forms including waste tyre rubber granules, waste tyre rubber chips, waste tyre rubber ash, etc.

Kim et al. ${ }^{18}$ reported the sorption capacity of granulated waste tyre rubber for several aromatic hydrocarbons. They observed that the comparative adsorption capacity of granulated rubber tyres for the different compounds were in the order; m-xylene > ethylbenzene > toluene $>$ trichloroethylene $>1,1,1$ trichloroethane $>$ chloroform. Park et al..$^{19}$ used the data reported by Kim et al. ${ }^{18}$ to test a soil-bentonite slurry cutoff wall which contained ground tires to mitigate the movement of organic compounds in water. They observed that the rubber particles in the slurry wall and not the soil-bentonite were primarily responsible for the adsorption of the organic compounds. Aisien et al. ${ }^{13}$ investigated the influence of operational parameters on the adsorption of ethylbenzene using waste tyre rubber granules and determined that the adsorption capacity of waste tyre rubber granules (WTRG) for ethylbenzene was indeed affected by contact time, initial concentration, adsorbent dosage, adsorbent particle size and temperature.

This study investigated the potential use of WTRG for the adsorption of naphthalene from
Correspondence: Andrew N. Amenaghawon, Department of Chemical Engineering, University of Benin, PMB 1154, Benin City, Nigeria.

Tel.: +234.8069275563.

E-mail: andrew.amenaghawon@uniben.edu

Key words: adsorption, naphthalene, kinetics, adsorption capacity, isotherm.

Contributions: FAA, in collaboration with ANA, designed the study; AIA performed the experiments while ANA and SAA managed the literature searches; ANA wrote the first draft of the manuscript; FAA provided analytical advice and manuscript correction. All authors read and approved the final manuscript.

Received for publication: 29 January 2014. Revision received: 11 March 2014.

Accepted for publication: 11 March 2014.

This work is licensed under a Creative Commons Attribution NonCommercial 3.0 License (CC BYNC 3.0).

(C) Copyright F.A. Aisien et al., 2014

Licensee PAGEPress, Italy

Journal of Xenobiotics 2014; 4:2264

doi:10.4081/xeno.2014.2264

aqueous solution. The effects of factors such as contact time, initial naphthalene concentration, adsorbent dosage, adsorbent particle size and temperature on the adsorption process were evaluated. The adsorption of naphthalene on WTRG was further elucidated by carrying out kinetic (pseudo-first-order, pseudo-second-order, and intra particle diffusion models) and isotherm studies using common isotherms such as Langmuir, and Freundlich isotherms.

\section{Materials and Methods}

\section{Preparation of adsorbent}

The waste tyres used for this study were collected from a waste tyre dumpsite in Uselu, Benin City, Nigeria. Dirt and other foreign materials were removed by washing the tyres with water and subsequently air-drying them. The cleaned sides of the tyre free from steel breeds were cut into sections with the aid of a hacksaw and later into small pieces using very sharp knives. The size of the tyre chips were further reduced using an electric grinding machine. The resulting tyre particles were mechanically sieved to obtain particles in the size range 2.36 to $0.212 \mathrm{~mm}$ using different sieve trays as shown in Table 1 . The tyre granules were then washed with distilled water to remove any foreign materials by agitating it with a mechanical shaker operating at $150 \mathrm{rpm}$ for $3 \mathrm{~h}$. It was subsequently oven dried at $60^{\circ} \mathrm{C}$ 
for $5 \mathrm{~h}$ and stored in airtight containers for subsequent use. ${ }^{13}$

Nitrogen adsorption method was used to determine the surface area of the WTRG (BET 624; Micromeritics Germany GmbH, Aachen, Germany). Micropore volume was determined using the 3-D pore size distribution model developed at the Illinois State Geological Survey/University of Illinois at UrbanaChampaign (ISGS/UIUC) while the total pore volume was determined at a relative pressure value of approximately 0.98 . Ultimate elemental analysis of the WTRG was carried out using standard American Society for Testing and Materials (ASTM) methods. The bulk density and porosity of the WTRG were determined using standard methods..$^{20}$

\section{Preparation of adsorbate}

Analytical reagent grade naphthalene, provided by Griffin and George Ltd. (Loughborough, UK) was used as the representative PAH. A stock solution of naphthalene was prepared by dissolving $1 \mathrm{~g}$ of naphthalene in $1 \mathrm{~L}$ of a binary solution comprising $50 \mathrm{~mL}$ of methanol (British Drug Houses Ltd., London, UK) and $950 \mathrm{~mL}$ of de-ionized water. Naphthalene is a hydrophobic compound with low solubility in water. The water-methanol solution was used instead of pure de-ionized water to enhance the solubility of hydrophobic naphthalene.,7 Working solutions of volume $100 \mathrm{~mL}$ with different concentrations of naphthalene were prepared by appropriate dilutions of the stock solution with distilled water immediately prior to their use. The dilutions were done by dispensing a quantity of the stock solution into $250 \mathrm{~mL}$ amber bottles according to Equation (1):

$C_{1} V_{1}=C_{2} V_{2}$

where:

$\mathrm{C}_{1}$, concentration of standard solution ( $\mathrm{mg} / \mathrm{L}$ );

$\mathrm{V}_{1}$, volume from standard solution in $(\mathrm{mL})$;

$\mathrm{C}_{2}$, required concentration in $(\mathrm{mg} / \mathrm{L})$;

$\mathrm{V}_{2}$, volume of required solution $(100 \mathrm{~mL})$.

\section{Analysis of naphthalene in aqueous solution}

A UV-Vis spectrophotometer (PG Instruments model T70) was used to determine the concentration of un-adsorbed naphthalene in the sorption medium at a wavelength of $276 \mathrm{~nm}$.

Table 1. Rubber gradation.

\begin{tabular}{lc} 
Sieve sire & (\% Passing) \\
$2.36 \mathrm{~mm}(\# 8)$ & 100 \\
$1.18 \mathrm{~mm}(\# 16)$ & 90 \\
\hline $0.60 \mathrm{~mm}(\# 30)$ & 75 \\
$0.425 \mathrm{~mm}(\# 40)$ & 50 \\
\hline $0.212 \mathrm{~mm}(\# 75)$ & 20 \\
\hline
\end{tabular}

\section{Batch adsorption equilibrium study}

Batch adsorption of naphthalene by waste tyre rubber granules was carried out in mechanically agitated $250 \mathrm{~mL}$ Erlenmeyer flasks with a working volume of $100 \mathrm{~mL}$. The appropriate quantity ( $2 \mathrm{~g}$ ) of WTRG was added to the aqueous solution of naphthalene of the desired concentration. The effects of contact time, initial naphthalene concentration, size of WTRG particles, adsorbent dosage, and temperature of solution on the adsorption capacity were investigated. At the end of each experiment the agitated solution mixture was filtered through a $0.45 \mu \mathrm{m}$ membrane and the residual concentration of naphthalene was determined spectrophotometrically. The amount of naphthalene adsorbed at time $t, q_{t}$ and equilibrium $q_{e}$ were calculated using the equations:

$$
\begin{aligned}
& q_{t}=\frac{V_{s}\left(C_{i}-C_{t}\right)}{W} \\
& q_{e}=\frac{V_{s}\left(C_{i}-C_{e}\right)}{W}
\end{aligned}
$$

where:

$q_{\mathrm{e}}$ and $q_{t}$ are the naphthalene concentrations in the solid phase at time $t$ and equilibrium respectively;

$C_{o}, C_{t}$, and $C_{e}$ are the initial concentration, the liquid-phase concentration at time $t$, and the equilibrium concentration of naphthalene, respectively;

$V_{s}$ is the volume of the aqueous solution and $\mathrm{W}$ is the mass of WTRG.

\section{Results and Discussion}

\section{Characterization of waste tyre rubber granules}

The properties of WTRG as obtained from proximate analysis are presented in Table $2 .^{21-23}$ Results of the ultimate elemental analysis of the WTRG are presented in Table $3 .{ }^{23-25}$ These results indicate that the principal constituent of WTRG was carbon which accounted for $86.5 \%$ of the weight of the granules followed by hydrogen which accounted for $6.64 \%$ as shown in Table 3 . The inorganic ash content of the WTRG was about $3 \%$ as indicated in
Table 3. The ash content is important because concentrations of trace species, especially metals, can affect the adsorptive properties of the WTRG. The values presented in Tables 2 and 3 are close to those reported in the literature. The surface area, bulk density, porosity, total and micro pore volume are presented in Table 4.

\section{Effect of contact time on the adsorption of naphthalene by waste tyre rubber granules}

Figure 1 shows the effect of contact time on the adsorption of naphthalene by WTRG. The trend observed show that the rate of adsorption was rapid initially and subsequently decreased to reach equilibrium after $60 \mathrm{~min}$. At equilibrium, there is no noticeable increase in the rate of adsorption. This is because the adsorbent is saturated and all available active binding sites are occupied by the naphthalene molecules. ${ }^{4,13}$ The equilibrium contact time of $60 \mathrm{~min}$ indicates fast adsorption of naphthalene by WTRG. The fast adsorption rate observed at the initial stage might have been as a result of the abundantly available active binding sites on the adsorbent surface. These sites are subsequently occupied by naphthalene molecules thereby resulting in the inability of the WTRG to remove naphthalene consequently leading to the decreased adsorption rates observed at the later stages of the adsorption process. ${ }^{13,26,27}$ Similar results and observations have been reported in the literature. Agarry et al. ${ }^{4}$ reported an equilibrium time of $80 \mathrm{~min}$ for the adsorption of naphthalene by modified spent tea leaves. Gunasekara et al. ${ }^{16}$ reported fast adsorption of naphthalene, toluene and mercury by ground waste tyres with an equilibrium time of $30 \mathrm{~min}$. Alam et al. reported an equilibrium contact time of $100 \mathrm{~min}$ for the abatement of organic pollutants such as 2,4-D and phenol using WTRG. An equilibrium contact time of $30 \mathrm{~min}$ was obtained for the removal of aromatic hydrocarbons such as ethylbenzene, toluene and xylene using granulated scrap tyre rubber as reported by Alamo-Nole et al. ${ }^{12}$ The structure and chemical composition of WTRG is a key determinant of its adsorptive properties. WTRG contains styrene amongst other functional groups. The aromatic ring in styrene enables interaction

Table 2. Properties of waste tyre rubber granules obtained from proximate analysis.

\begin{tabular}{lcccc} 
Property & \multicolumn{3}{c}{ Value (wt\%) } \\
& Present study & Lee et al. ${ }^{21}$ & Chang ${ }^{22}$ & Gonzalez et al. ${ }^{23}$ \\
Fixed carbon & 28.35 & 28.50 & 26.26 & 29.20 \\
Moisture & 0.51 & 0.50 & 1.31 & 0.70 \\
\hline Ash & 7.60 & 3.7 & 10.29 & 8.0 \\
Volatile & 63.54 & 67.30 & 62.32 & 61.90 \\
\hline
\end{tabular}


between styrene and naphthalene in aqueous solution. The increased affinity of the WTRG for naphthalene resulting from the interaction might explain the fast removal of naphthalene by WTRG. ${ }^{28}$

\section{Effect of initial naphthalene concentration on the adsorption of naphthalene by waste tyre rubber granules}

The initial concentration of the adsorbate is an important factor that must be considered during adsorption as it affects the adsorption process to a large extent. The efficiency of WTRG in removing naphthalene from aqueous solution was presented in Figure 2. It was observed that the adsorption capacity of WTRG for naphthalene increased with increase in the concentration of naphthalene for all the concentrations studied. The trend observed might be due to the increase in the concentration gradient between the solid phase (adsorbent) and aqueous phase (adsorbate) which resulted from the increase in the concentration of naphthalene. The increased concentration gradient consequently leads to an increased driving force which overcomes the resistance to mass transfer between the solid and aqueous phases..$^{13,29}$ Similar results have been reported in the literature. Alade et al..$^{30}$ reported an upward trend for the uptake of naphthalene using activated carbon. Mahvi et al..$^{27}$ reported similar trends for the uptake of phenol from aqueous solution using rice husk and rice husk ash. Agarry et al. ${ }^{4}$ also indicated an increase in the adsorption of naphthalene with increase in concentration using spent tea leaves.

\section{Effect of adsorbent dosage on the adsorption of naphthalene by waste tyre rubber granules}

The effect of adsorbent dosage on the adsorption of naphthalene by WTRG is presented in Figure 3. In general, it was observed that the adsorption capacity increased with increase in adsorbent dosage indicating that the adsorbent dose had a significant influence on the adsorption process. Increasing the adsorbent dose resulted in an enhancement of the adsorption of

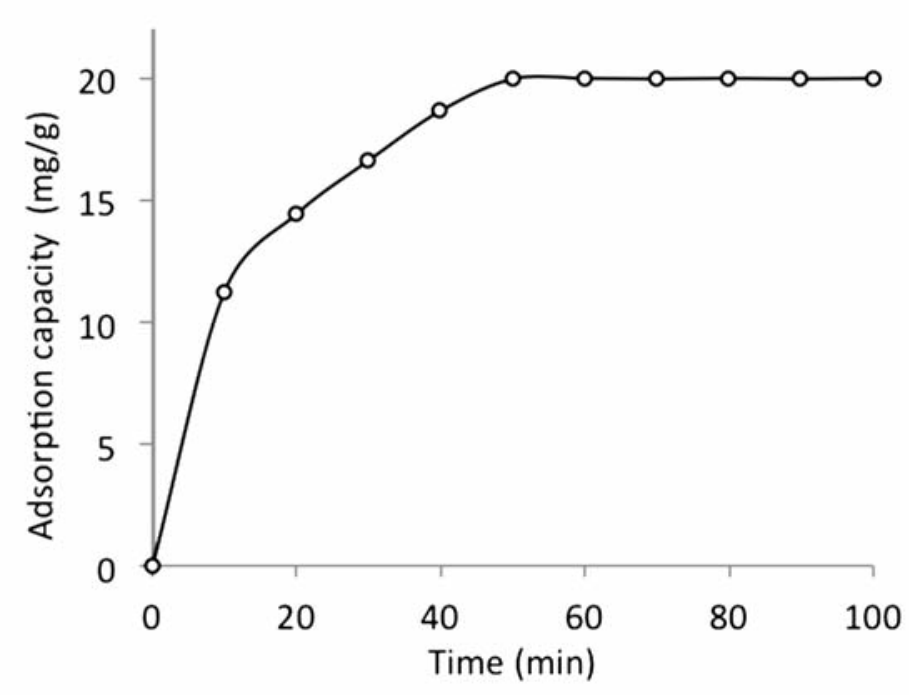

Figure 1. Effect of contact time on the adsorption capacity of waste tyre rubber granules (WTRG) ( $\mathrm{pH} 7$; initial concentration, $800 \mathrm{mg} / \mathrm{L}$; WTRG dose, $2 \mathrm{~g}$; particle size, 0.212 $\mathrm{mm}$; temperature, $20^{\circ} \mathrm{C}$ ).
Table 3. Ultimate elemental analysis of waste tyre rubber granules.

\begin{tabular}{lcccc} 
Property & \multicolumn{3}{c}{ Value (wt\%) } \\
& Present study & Roy et al. ${ }^{24}$ & Senneca et al. ${ }^{25}$ & Gonvales et al. ${ }^{23}$ \\
Carbon & 86.50 & 86.6 & 86.7 & 86.7 \\
Hydrogen & 6.64 & 8.1 & 6.9 & 8.1 \\
\hline Oxygen & 1.10 & 2.2 & 1.0 & 1.3 \\
Nitrogen & 0.40 & 0.5 & 0.3 & 0.4 \\
\hline Sulphur & 2.0 & 0.8 & 1.9 & 1.4 \\
Inorganic ash & 2.85 & - & 3.3 & 2.9 \\
\hline
\end{tabular}

Table 4. Physical properties of waste tire rubber granule.

\begin{tabular}{ll} 
Property & Value \\
Surface area $\left(\mathrm{m}^{2} / \mathrm{g}\right)$ & 0.203 \\
Bulk density $\left(\mathrm{g} / \mathrm{cm}^{3}\right)$ & 0.230 \\
\hline Porosity & 0.130 \\
Total pore volume $\left(\mathrm{cm}^{3} / \mathrm{g}\right)$ & 0.660 \\
\hline Micro pore volume $\left(\mathrm{cm}^{3} / \mathrm{g}\right)$ & 0.230 \\
\hline
\end{tabular}


naphthalene. This was probably as a result of the increase in the adsorptive surface area leading to the availability of more active binding sites. ${ }^{31,32}$ Zafar et al.$^{33}$ reported that the amount of adsorbent added into the solution determines the number of binding sites available for adsorption. Mousavi et al. ${ }^{15}$ reported enhanced uptake of lead ions from aqueous solution when the dose of waste tyre rubber ash was increased. Also, Aisien et al $^{34}$ reported the increased uptake of crude oil as the quantity of recycled rubber was increased.

\section{Effect of adsorbent particle size} the adsorption of naphthalene by waste tyre rubber granules

Figure 4 shows the effect of adsorbent particle size on the adsorption capacity of WTRG for naphthalene. It was observed the adsorption of naphthalene by WTRG increased with a decrease in the size of WTRG particles. The maximum adsorption capacity was observed at a particle size of $0.212 \mathrm{~mm}$. The trend observed might be as a result of the increase in the interior surface area and micro pore volume and consequently more active sites for adsorption. However, for larger particles, the pore diffusion resistance to mass transfer is higher and most of the internal surfaces of the particle may not be utilized for adsorption and consequently the amount of naphthalene adsorbed is small. ${ }^{35}$ Smith et al. ${ }^{36}$ reported that smaller chips from recycled tyre rubber had higher adsorption capacity for phenol and p-cresol indicating the influence of adsorbent particle size and consequently the surface area on the sorption process. Aisien et al..$^{13}$ reported similar results for the adsorption of ethylbenzene using WTRG. Agarry and Owabor ${ }^{26}$ also reported similar findings for the treatment of abattoir wastewater and removal of iron (III) ions using activated carbon made from rubber seed shells.

\section{Effect of solution temperature}

\section{the adsorption of naphthalene}

\section{by waste tyre rubber granules}

The effect of temperature on the adsorption of naphthalene by WTRG is presented in Figure 5. The results show that the adsorption capacity of WTRG for naphthalene decreased from 19.99 to $15 \mathrm{mg} / \mathrm{g}$ with increase in temperature from 5 to $40^{\circ} \mathrm{C}$. This indicated that a lower temperature was more favorable for the adsorption of naphthalene by WTRG. At low temperatures, the naphthalene molecules have less kinetic energy and will be able to migrate deeper into the WTRG micro-structure; hence more naphthalene will be retained by the adsorbent. However, at higher temperatures, the attractive force between the naphthalene molecules and the WTRG is weakened on the one hand and thermal energies of the naphthalene molecules are enhanced on the other hand thus making the attractive force between

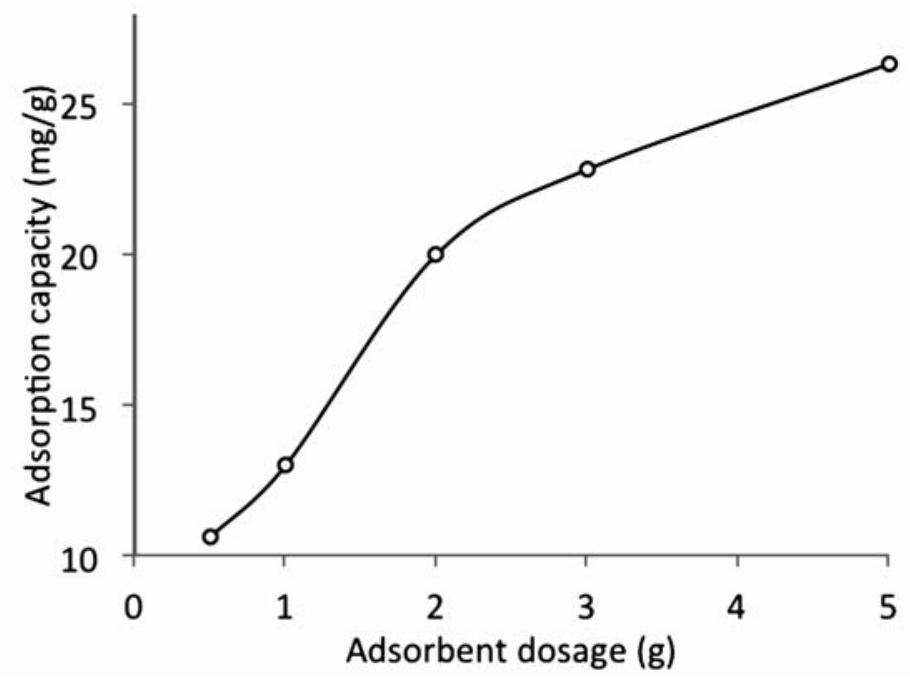

Figure 3. Effect of adsorbent dosage on the adsorption capacity of waste tyre rubber granules ( $\mathrm{pH}$ 7; initial concentration, $800 \mathrm{mg} / \mathrm{L}$; particle size, $0.212 \mathrm{~mm}$; temperature, $20^{\circ} \mathrm{C}$ ).

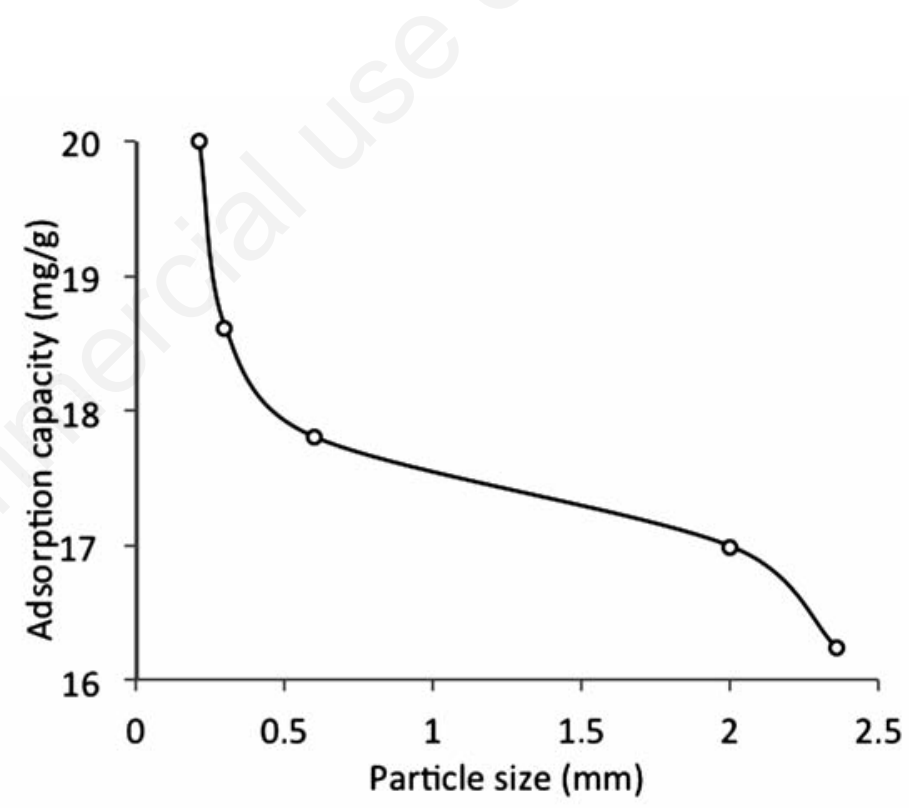

Figure 4. Effect of adsorbent particle size on the adsorption capacity of waste tyre rubber granules (WTRG) (pH 7; WTRG dose, 2 g; initial concentration, $800 \mathrm{mg} / \mathrm{L}$; temperature, $\left.20^{\circ} \mathrm{C}\right)$.

the naphthalene molecules and the WTRG insufficient to retain the adsorbed molecules at the binding sites. ${ }^{37}$ Mousavi et al. ${ }^{15}$ reported a similar trend and suggested that the inverse relationship between adsorption capacity and temperature is indicative of physical and exothermic adsorption.

\section{Modeling the kinetics of adsorption}

The kinetics of adsorption is useful in elucidating the mechanism of the adsorption process.
The Lagergren pseudo first-order, pseudo second-order and intra particle diffusion kinetic models were applied to the data obtained for adsorption of naphthalene by WTRG.

\section{Lagergren pseudo first-order kinetic model}

The Lagergren rate equation is one of the most widely used kinetic equations for the adsorption of a solute from a liquid solution. ${ }^{38}$ The model assumes a first order adsorption 
kinetics and can be represented by the equation:

$$
\frac{d q_{t}}{d t}=k_{1}\left(q_{e}-q_{t}\right)
$$

where:

$q_{e}$ and $q_{t}$ are adsorption capacity at equilibrium and at time $t$, respectively $(\mathrm{mg} / \mathrm{g})$;

$k_{1}$ is the rate constant of pseudo first order adsorption $\left(\mathrm{min}^{-1}\right)$.

After integration and applying boundary conditions $t=0$ to $t=t$ and $q_{t}=0$ to $q_{t}=q_{t}$, the integrated form of Equation (4) becomes:

$$
\ln \left(q_{e}-q_{f}\right)=\ln q_{e}-k_{1} t
$$

The values of $\ln \left(q_{e}-q_{t}\right)$ were plotted as a function of $t$. The plot of $\ln \left(q_{e}-q_{t}\right)$ versus $t$ resulted in a linear relationship as shown in Figure 6 from which $k_{l}$ and $q_{e}$ were determined from the slope and intercept respectively. The first order rate constants calculated from the plot are given in Table 5 .

\section{Pseudo second-order kinetic model}

The pseudo-second order kinetic model which is based on the assumption that chemisorption is the rate-determining step can be expressed as in Equation (6):

$$
\frac{d q_{t}}{d t}=k_{2}\left(q_{e}-q_{t}\right)^{2}
$$

where:

$k_{2}$ is the rate constant of the pseudo second order adsorption (g.mg-1 $\mathrm{min}^{-1}$ ).

After integration and applying boundary conditions $t=0$ to $t=t$ and $q_{t}=0$ to $q_{t}=q_{e}$, the integrated form becomes:

$\frac{1}{\left(q_{e}-q_{f}\right)}=\frac{1}{q_{e}}+k_{2} t$

Equation (7) can be rearranged to a linear form as shown in Equation (8).

$\frac{t}{q_{t}}=\frac{1}{h}+\frac{1}{q_{e}} t$

The initial adsorption rate, $h\left(\mathrm{mg} \cdot \mathrm{g}^{-1} \cdot \mathrm{min}^{-1}\right)$ is given as:

$$
h=k_{2} q_{e}^{2}
$$

The plot of $\left(t / \mathrm{q}_{\mathrm{t}}\right)$ and $t$ of Equation (8) as presented in Figure 7 resulted in a linear relationship from which $q_{e}$ and $k_{2}$ were calculated. These values are given in Table 5 .

\section{Intra particle diffusion model}

The intra particle diffusion kinetic mode ${ }^{39}$ can be written as presented in Equation (10):

$$
q_{t}=K_{p} t^{1 / 2}+C
$$

$K_{p}$ is the intra particle diffusion rate constant $\left(\mathrm{mgg}^{-1} \mathrm{~min}^{-1 / 2}\right.$ ) and $C$ is the intercept of the plot which is indicative of the boundary layer thickness. If the intercept is greater than zero, it indicates the existence of some boundary

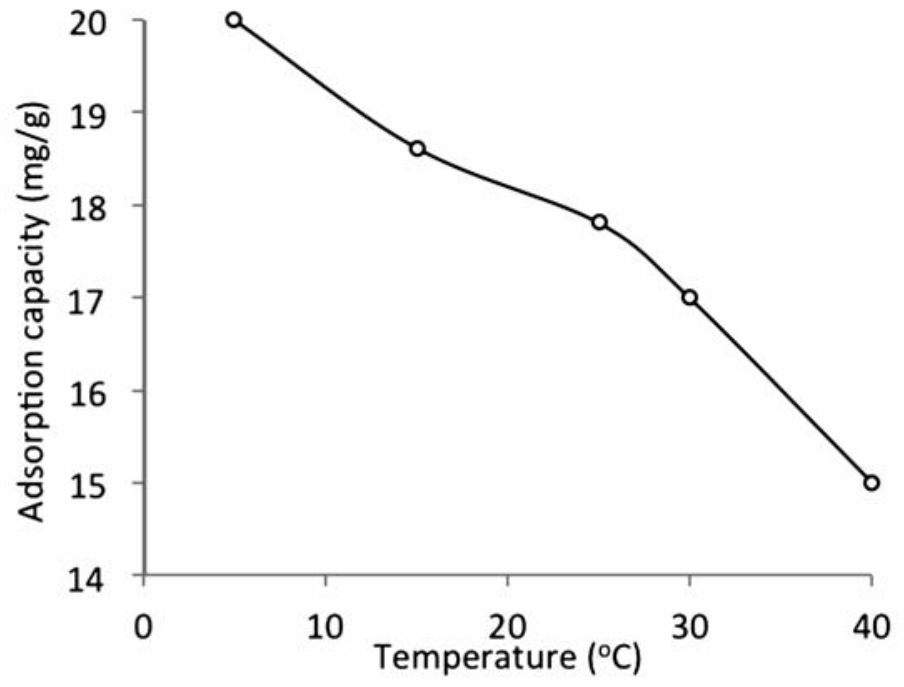

Figure 5. Effect of temperature on the adsorption of naphthalene by waste tyre rubber granules (WTRG) ( $\mathrm{pH} 7$; initial concentration, $800 \mathrm{mg} / \mathrm{L}$; WTRG dose, 2 g; particle size, $0.212 \mathrm{~mm}$ ).

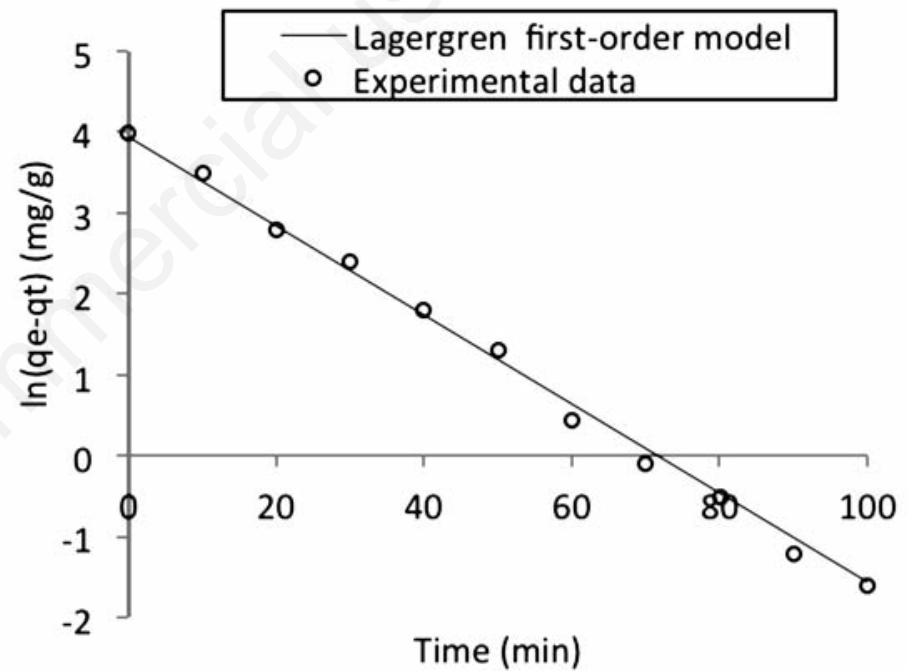

Figure 6. Lagergren first-order kinetic model fitted to the batch adsorption data obtained for naphthalene adsorption by waste tyre rubber granules.

Table 5. Parameter values for pseudo first order, pseudo second order and intraparticle diffusion models.

\begin{tabular}{lcc} 
Adsorption kinetic model & Parameters & Values \\
Lagergren pseudo first-order & $k_{l}\left(\mathrm{~min}^{-1}\right)$ & 0.057 \\
& $q_{e}(\mathrm{mg} / \mathrm{g})$ & 56.49 \\
$R^{2}$ & 0.997 \\
Pseudo second-order & $k_{2}\left(\mathrm{gmg}^{-1} \mathrm{~min}^{-1}\right)$ & 0.006 \\
& $q_{e}(\mathrm{mg} / \mathrm{g})$ & 22.22 \\
& $R^{2}$ & 0.995 \\
\hline Intra particle diffusion & $K_{p}$ & 2.005 \\
& $C$ & 3.767 \\
& $R^{2}$ & 0.899
\end{tabular}


layer effect and shows that intra-particle diffusion is not the only rate-limiting step. This was indeed the case for the $q_{t}$ versus $t^{1 / 2}$ plot presented in Figure 8. The calculated diffusion coefficient values are presented in Table 5 .

In this study, the Lagergren pseudo first order and pseudo second order kinetic models fitted well to the adsorption kinetic data with relatively high correlation coefficients. However, the intra particle diffusion kinetic model did not result in a good fit with the data as seen in the lower value of the correlation coefficient. The Lagergren pseudo first-order model gave the best fit with the highest correlation coefficient to describe the adsorption behaviour of naphthalene by WTRG.

\section{Isotherm studies}

Adsorption isotherms were used to describe the equilibrium between the concentration of naphthalene in the aqueous phase and that in the solid (adsorbent) phase. A number of isotherm equations have been developed to describe equilibrium relationships. The Langmuir and Freundlich isotherm equations were utilized for this study.

\section{Langmuir isotherm}

The Langmuir isotherm equation is applied for monolayer adsorption onto an adsorptive surface containing homogeneously distributed active sites. ${ }^{40}$ The equation contains two useful parameters $\left(q_{o}\right.$ and $b$ ), which reflect the two important characteristics of the sorption system. It provides information on uptake capabilities and is capable of reflecting the usual equilibrium adsorption process behavior. The linear form of the Langmuir equation is given as:

$$
\frac{C_{e}}{q_{e}}=\frac{1}{b q_{o}}+\frac{C_{e}}{q_{o}}
$$

$q_{o}$ is the maximum sorption capacity ( $\mathrm{mg} / \mathrm{g}$ ) of the adsorbent while $b$ is the sorption constant $(\mathrm{L} / \mathrm{mg})$ at a given temperature. A linear plot of $C_{e} / q_{e}$ against $C_{e}$ as shown in Figure 9 was employed to obtain the values of $q_{0}$ and $b$ from the slope and intercept of the plot respectively. The values of the Langmuir isotherm parameters as well as the correlation coefficient $\left(\mathrm{R}^{2}\right)$ of the Langmuir equation for the adsorption of naphthalene by WTRG are given in Table 6 . The values of these parameters were close to those reported by Agarry et al. ${ }^{4}$ and Tsyntsarski et al. ${ }^{41}$ for the adsorption of naphthalene by spent tea leaves and activated carbon produced from biomass and coal wastes respectively. The separation factor $\left(\mathrm{R}_{\mathrm{L}}\right)$ can be used to describe the characteristics of the Langmuir isotherm equation. ${ }^{42,43}$ The value of this dimensionless constant defined in Equation (12) determines whether the adsorption process is favorable or otherwise.

$$
R_{L}=\frac{1}{\left(1+b C_{o}\right)}
$$

$C_{o}$ is the initial concentration of naphthalene.
The dependence of the nature of adsorption on the value of $R_{L}$ is presented in Table 7 .

For the present study, the values of $R_{L}$ obtained at different initial naphthalene con-
Table 6. Kinetic parameters for Langmuir and Freundlich isotherms.

\begin{tabular}{cccccc} 
& \multicolumn{3}{c}{ Langmuir isotherm } & \multicolumn{3}{c}{ Freundlich isotherm } \\
$q_{0}(\mathrm{mg} / \mathrm{g})$ & $\mathrm{b}(\mathrm{L} / \mathrm{mg})$ & $\mathrm{R}^{2}$ & $\mathrm{~K}_{\mathrm{f}}(\mathrm{mg} / \mathrm{g})$ & $\mathrm{n}$ & $\mathrm{R}^{2}$ \\
21.74 & 0.055 & 0.998 & 0.189 & 1.348 & 0.992 \\
\hline
\end{tabular}

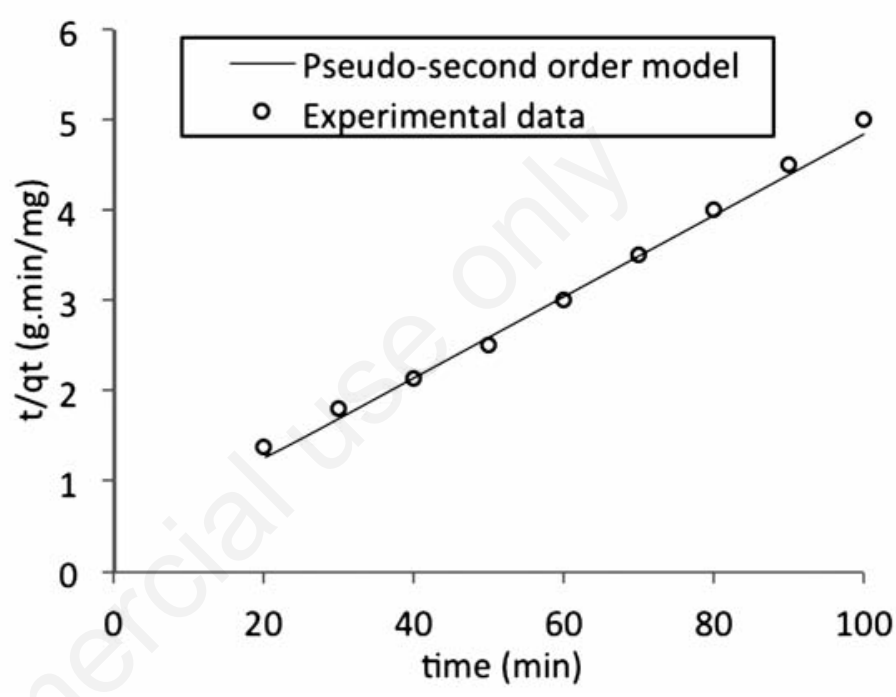

Figure 7. Pseudo second order kinetic model fitted to the batch adsorption data obtained for naphthalene adsorption by waste tyre rubber granules.

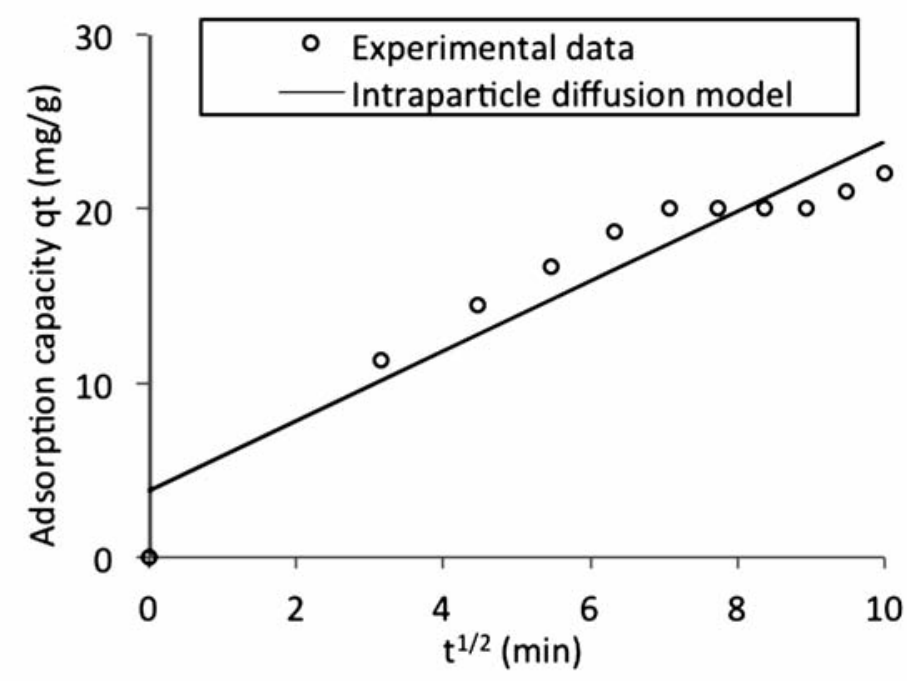

Figure 8. Intra particle diffusion model fitted to the batch adsorption data obtained for naphthalene adsorption by waste tyre rubber granules. 
centrations are presented in Table 8. These values are between zero and one indicating that the adsorption was favorable.

\section{Freundlich isotherm}

The Freundlich isotherm is an empirical equation employed to describe heterogeneous systems. It is expressed in its non-linear form as:

$$
q_{e}=K_{f}\left(C_{e}\right)^{1 / n}
$$

This equation can be expressed in linear form as follows:

$$
\ln q_{e}=\ln K_{f}+1 / n \ln C_{e}
$$

$K_{f}$ and $n$ are the Freundlich constants related to the adsorption capacity and adsorption intensity respectively. These parameters were determined respectively from the intercept and slope of the linear plot of $\ln q_{e}$ against $\ln C_{e}$ at given experimental conditions as shown in Figure 10. Values of $n$ between 1 and 10 represent favorable adsorption. ${ }^{4}$ The values of these parameters as well as the correlation coefficient $\left(R^{2}\right)$ of the Freundlich equation for the adsorption of naphthalene by WTRG are given in Table 6 . Values of $K_{f}$ and $n$ have been reported in the literature. $\mathrm{Pal}^{44}$ reported $K_{f}$ and $n$ values of 0.3 and $1.12,0.025$ and 1.47 for the adsorption of naphthalene by sugarcane bagasse and rice husk respectively. Agarry et al. ${ }^{4}$ reported $K_{f}$ and $n$ values 2.44 and 1.85 respectively.

Generally, the results presented in Table 6 indicate that the adsorption data fitted the both the Langmuir and Freundlich isotherm equations. However a better fit resulted for the Langmuir isotherm equation as evident in the higher $\mathrm{R}^{2}$ value obtained. This suggests that the adsorption of naphthalene by WTRG is of the mono-layer type. Similar observations have been reported for the adsorption of aromatics by WTRG and other adsorbents. , $, 7,13,41^{2}$

\section{Conclusions}

The present study investigated the potential use of waste tyre rubber granules for the batch adsorption of naphthalene from aqueous solutions. The following conclusions can be drawn.

- Adsorption of naphthalene by WTRG is influenced by factors such as contact time, initial naphthalene concentration, adsorbent dosage, adsorbent particle size and solution temperature.

- The equilibrium contact time was obtained as 60 min indicating a fast adsorption process.

- A low temperature $\left(5^{\circ} \mathrm{C}\right)$, small adsorbent particle size $(0.212 \mathrm{~mm})$ and higher adsorbent dosage favored the adsorption process with removal capacities of $19.99,20$ and $26.32 \mathrm{mg} / \mathrm{g}$ respectively.

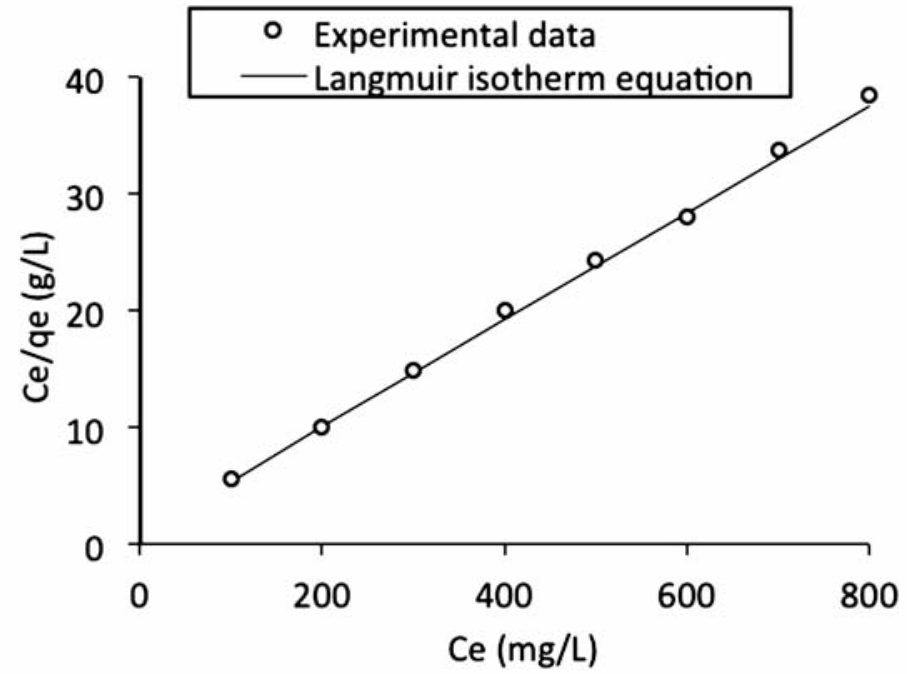

Figure 9. Langmuir isotherm fitted to the batch adsorption data obtained for naphthalene adsorption by waste tyre rubber granules.

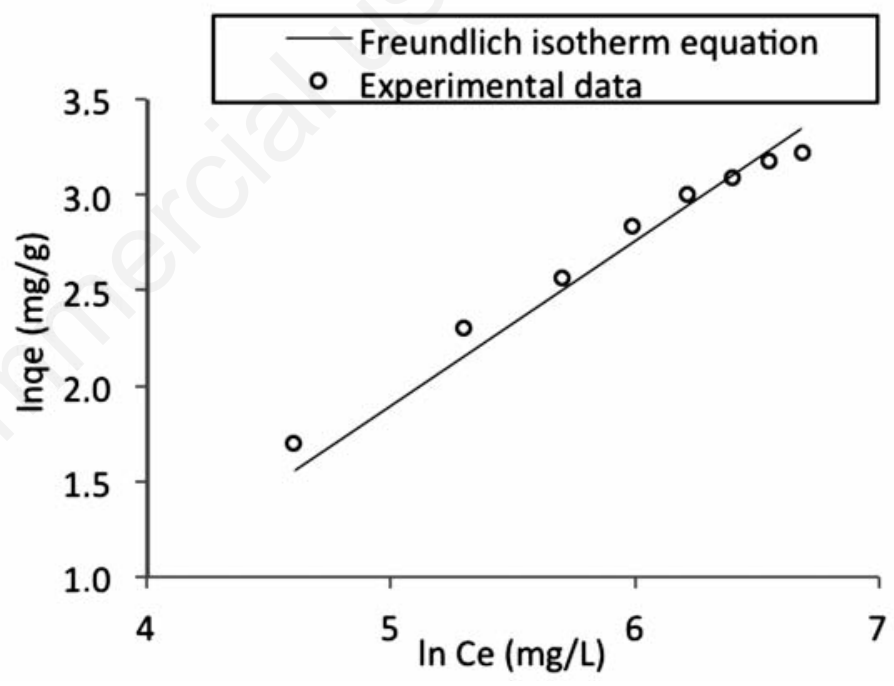

Figure 10. Freundlich isotherm fitted to the batch adsorption data obtained for naphthalene adsorption by waste tyre rubber granules.

Table 7. $R_{L}$ values and type of isotherm.

\begin{tabular}{lc}
$R_{L}$ & Type of isotherm \\
$R_{L}>1$ & Unfavorable \\
$R_{L}=1$ & Linear \\
$0<R_{L}<1$ & Favorable \\
$R_{L}=0$ & Irreversible \\
\hline$R_{L}$ separation factor. &
\end{tabular}

Table 8. $R_{L}$ values and type of isotherm.

\begin{tabular}{lc} 
Initial concentration (mg/L) & $\mathbf{R}_{\mathrm{L}}$ value \\
\hline 100 & 0.154 \\
200 & 0.083 \\
\hline 300 & 0.057 \\
400 & 0.043 \\
\hline 500 & 0.035 \\
600 & 0.029 \\
\hline 700 & 0.025 \\
800 & 0.022 \\
\hline
\end{tabular}

$\mathrm{R}_{\mathrm{L}}$, separation factor. 
- The adsorption equilibrium data fitted well to the Langmuir isotherm equation indicating mono layer type adsorption.

- The kinetics of the adsorption process was well described by the Lagergren pseudo-first order kinetic model.

This study has demonstrated that the low cost WTRG can be used for removal of naphthalene from aqueous solution.

\section{Research highlights}

The amount of waste tyre generated annually in Nigeria is on the increase as a result of the increase in vehicular traffic. These waste tyres are typically disposed of inappropriately thereby constituting environmental problems. Naphthalene is a toxic organic pollutant found in most industrial effluents. This research work aims to add value to waste tyres by using it in granulated form as an adsorbent for the removal of naphthalene from aqueous solutions.

\section{References}

1. Bamforth SM, Singleton I. Bioremediation of polycyclic aromatic hydrocarbons: current knowledge and future directions. $\mathrm{J}$ Chem Technol Biotechnol 2005;80:723-36.

2. Li Z, Mulholland JA, Romanoff LC, Pittman EN, Trinidad DA, Lewin MD, et al. Assessment of non-occupational exposure to polycyclic aromatic hydrocarbons through personal air sampling and urinary biomonitoring. J Environ Monitor 2010;12: 1110-8.

3. Wilson NK, Chuang JC, Lyu C, Menton R, Morgan MK. Aggregate exposures of nine preschool children to persistent organic pollutants at day care and at home. J Expo Sci Env Epid 2003;13:187-202.

4. Agarry SE, Ogunleye 00, Aworanti OA. Biosorption equilibrium, kinetic and thermodynamic modelling of naphthalene removal from aqueous solution onto modified spent tea leaves. Environ Technol 2013;34:825-39.

5. US Environmental Protection Agency. Health effects assessment for naphthalene, EPA/540/1D86/ 014. Cincinnati, OH: Environmental Criteria and Assessment Office, Office of Health and Environmental Assessment, Office of Research and Development; 1986.

6. Ania CO, Cabal B, Pevida C, Arenillas A, Parra JB, Rubiera F, et al. Removal of naphthalene from aqueous solution on chemically modified activated carbons. Water Res 2007;41:333-40.

7. Chang CF, Chang CY, Chen KH, Tsai WT, Shie JL, Chen YH. Adsorption of naphthalene on zeolite from aqueous solution. J Colloid Interf Sci 2004;277:29-34.
8. Cooper WJ, Nickelsen MG, Green RV, Mezyk SP. The removal of naphthalene from aqueous solutions using high-energy electron beam irradiation. Radiat Phys Chem 2002;65:571-7.

9. Legube B, Guyon S, Sugimitsu H, Dore M. Ozonation of naphthalene in aqueous solution- i: ozone consumption and ozonation products. Water Res WATRAG 1986;20(2).

10. Ohno T, Tokieda K, Higashida $\mathrm{S}$, Matsumura M. Synergism between rutile and anatase $\mathrm{TiO} 2$ particles in photocatalytic oxidation of naphthalene. Appl Catal A General 2003;244:383-91.

11. Liu Z, Jacobson AM, Luthy RG. Biodegradation of naphthalene in aqueous nonionic surfactant systems. Appl Environ Microb 1995;61:145-51.

12. Alamo-Nole LA, Perales-Perez 0, RomanVelazquez FR. Sorption study of toluene and xylene in aqueous solutions by recycled tires crumb rubber. J Hazard Mater 2011;185:107-11.

13. Aisien FA, Amenaghawon NA, Akhidenor SA. Adsorption of ethylbenzene from aqueous solution using recycled rubber from scrap tyre. J Sci Res Rep 2013;2:497-12.

14. Aisien FA, Hymore FK, Ebewele RO. Application of ground scrap tyre rubbers in asphalt concrete pavement. Indian J Eng Mater S 2006;13:333-8.

15. Mousavi HZ, Hosseynefar A, Jaheed V, Dehghani SA. Removal of lead from aqueous solution using waste tyre rubber ash as adsorbent. Braz J Chem Eng 2010;27:79-87.

16. Gunasekara AS, Donovan JA, Xing B. Ground discarded tires remove naphthalene, toluene, and mercury from water. Chemosphere 2000;41:1155-60.

17. Alam MJB, Chowdhuary RK, Hasan MM, Huda A, Sobhan S. Study and simulation of competitive sorption of 2,4,-D and phenol on waste tire rubber granules. ARPN J Eng Appl Sci 2006;1:45.

18. Kim J, Park J, Edil T. Sorption of organic compounds in the aqueous phase onto tire rubber. J Environ Eng 1997;123:827-35.

19. Park JK, Kim JY, Madsen CD, Edil TB. Retardation of volatile organic compound movement by a soil-bentonite slurry cutoff wall amended with ground tires. Water Environ Res 1997;69:1022-31.

20. APHA-AWWA-WPCF. Standard methods for the examination of water and wastewater. New York, NY: American Public Health Association; 1989.

21. Lee JM, Lee JS, Kim JR, Kim SD. Pyrolysis of waste tires with partial oxidation in a fluidized-bed reactor. Energy 1995;20:969-76.

22. Chang YM. On pyrolysis of waste tire: degradation rate and product yields. Resour Conserv Recy 1996;17:125-39.

23. González JF, Encinar JM, Canito JL, Rodŕguez JJ. Pyrolysis of automobile tyre waste. Influence of operating variables and kinetics study. J Anal Appl Pyrol 2001; 58:667-83.

24. Roy C, Darmstadt H, Benallal B. AmenChen C. Characterization of naphtha and carbon black obtained by vacuum pyrolysis of polyisoprene rubber. Fuel Process Technol 1997;50:87-103.

25. Senneca 0, Salatino P, Chirone, R. A fast heating-rate thermogravimetric study of the pyrolysis of scrap tyres. Fuel 1999;78: 1575-81.

26. Agarry SE, Aremu MO. Batch equilibrium and kinetic studies of simultaneous adsorption and biodegradation of naphthalene by orange peels immobilized Pseudomonas aeruginosa NCIB 950. J Bioremed Biodegrad 2012;3:138-41.

27. Mahvi AH, Maleki A, Eslami A. Potential of rice husk ash for phenol removal in aqueous systems. Am J Appl Sci 2004;1:321-26.

28. Alamo-Nole LA. Sorption of ethyl benzene, toluene and xylene onto crumb rubber from aqueous solutions. MSc Thesis, University of Puerto-Rico; 2006.

29. Agarry SE, Owabor CN. Evaluation of the adsorption potential of rubber (havea brasiliensis) seed pericarp-activated carbon in abattoir wastewater treatment and in the removal of iron (III) ions from aqueous solution. Niger J Technol 2012; 31:346-58.

30. Alade AO, Amuda OS, Afolabi TJ, Okoya AA. Adsorption of naphthalene onto activated carbons derived from milk bush kernel shell and flamboyant pod. J Environ Chem Ecotoxicol 2012;4:124-32.

31. Nagda GK, Diwan AM, Ghole VS. Potential of tendu leaf refuse for phenol removal in aqueous system. Appl Ecol Environ Res 2007;5:1-9.

32. Nasuha N, Hameed BH, Din ATM. Rejected tea as a potential low cost adsorbent for the removal of methylene blue. J Hazard Mater 2010;175:126-32.

33. Zafar MN, Nadeem R, Hanif MA. Biosorption of nickel from protonated rice bran. J Hazard Mater 2007;143:478-85.

34. Aisien FA, Hymore FK, Ebewele RO. Potential application of recycled rubber in oil pollution control. Indian J Eng Mater S 2002;11:179-90.

35. Annadurai G, Rajesh BS, Mahesh KPO, Murugesan T. Adsorption and biodegradation of phenol by chitosan-immobilised pseudomonas putida. Bioprocess Eng 2000;22:493-501.

36. Smith CC, Anderson WF, Freewood RJ. Evaluation of shredded tyre chips as sorption media for passive treatment walls. Eng Geol 2001;60:253-61.

37. Jadhav DN, Vangara AK. Removal of phenol from wastewater using sawdust and sawdust carbon. Indian J Chem Techn 
2004;11:35-45.

38. Lagergren S. Zur theorie der sogenannte, adsorption geloster stoffe, Kungliga Svenska vetenskaps akademiens. Handlingar 1898;24:1-39.

39. Weber WJ, Morris JC. Kinetics of adsorption on carbon from solution. J Sanit Eng Div Am Soc Civil Eng 1963;89:31-60.

40. Langmuir I. The adsorption of gases on plane surfaces of glass, mica and platinum. J Am Chem Soc 1914;40:361-8.
41. Tsyntsarski B, Petrova B, Budinova T, Petrov N, Velasco L, Ania C0. Characterization and application of activated carbon from biomass and coal wastes for naphthalene removal. Bulg Chem Comm 2011;43:552-7.

42. Anirudhan TS, Radhakrishnan PG. Thermodynamics and kinetics of adsorption of $\mathrm{Cu}$ (II) from aqueous solutions onto a new cation exchanger derived from tamarind fruit shell. J Chem Thermodyn
2008;40:702-9.

43. Ozcan A, Ozcan AS. Adsorption of acid red 57 from aqueous solutions onto surfactant modified sepiolite. J Hazard Mater 2005; 125:252-9.

44. Pal D. Adsorption of polycyclic aromatic hydrocarbons using agricultural wastes: In: Effect of lignin content, International Conference on Chemical, Ecology and Environmental Sciences (ICEES 2012), 2012 March 17-18, Bangkok, Thailand. 